\title{
Electrical Structure of Garhwal Himalayan region, India, inferred from Magnetotelluric
}

\author{
M Israil*, DK Tyagi, PK Gupta and Sri Niwas \\ Department of Earth Sciences, Indian Institute of Technology Roorkee, Roorkee- 247667, INDIA \\ ^For correspondence, email: mohdfes@iitr.ernet.in
}

Magnetotelluric investigations have been carried out in the Garhwal Himalayan corridor to delineate electrical structure of the crust along a profile extending from Indo-Gangetic Plane to Higher Himalayan region in Uttarakhand, India. The profile passing through major Himalayan thrusts: Himalayan Frontal Thrust (HFF), Main Boundary Thrust (MBT) and Main Central Thrust (MCT), and is nearly perpendicular to the regional geological strike. These Himalayan thrusts are broadly parallel to each other, steeper near surface and become shallow with the depth until they merge with the detachment surface. The main tectonic elements of Garhwal Himalayan region have an average strike of NW-SE (Khattri 1992). Magneto-variation (MV) studies (Arora et al 1982), were carried out over a rectangular array of 24 stations in the Siwalik Himalayan region, indicated the presence of a conductive anomaly, which they interpreted as an extension of the Aravallis and referred to as Trans Himalayan conductor. Subsequently, MT investigations were carried out by Gupta et al (1994) in the Siwalik region over $150 \mathrm{~km}$ long Mohand - Ramnagar profile to determine the thickness of Siwalik sediments. They recorded MT data in the frequency range $0.01-100 \mathrm{~Hz}$ using short period MT system and estimated geoelectric strike of $\mathrm{N} 800 \mathrm{~W}$ on the basis of simple rotation of impedance tensor

We have conducted a Broadband MT survey in the Garhwal Himalayan corridor during 2004-06, data were recorded in the frequency band $1000-.001 \mathrm{~Hz}$. The locations of the 44 stations are shown in figure 1 . The paper presents the electrical structure of the crust along the profile inferred from the $2 \mathrm{D}$ smooth inversion of MT data.

The recorded time domain data were transformed to the frequency domain impedance tensor and subsequently used to determine intrinsic dimensionality and directionality of the geological structure with respect to the geographical coordinate system. We have used Groom and Bailey (1989) tensor decomposition as implemented by McNeice and Jones, 2001 in strike code provided by Alan G. Jones. The decomposition analysis suggests an average strike direction of $\mathrm{N} 700 \mathrm{~W}$ for entire profile. The measured responses are rotated in the estimated strike direction to obtain TE and TM response for inversion.

Smooth inversion of only TE mode, TM mode and joint TE and TM responses have been done so as the final model incorporates the important features of both TE and TM responses. The main results are given in figure 2 which presents (i) $2 \mathrm{D}$

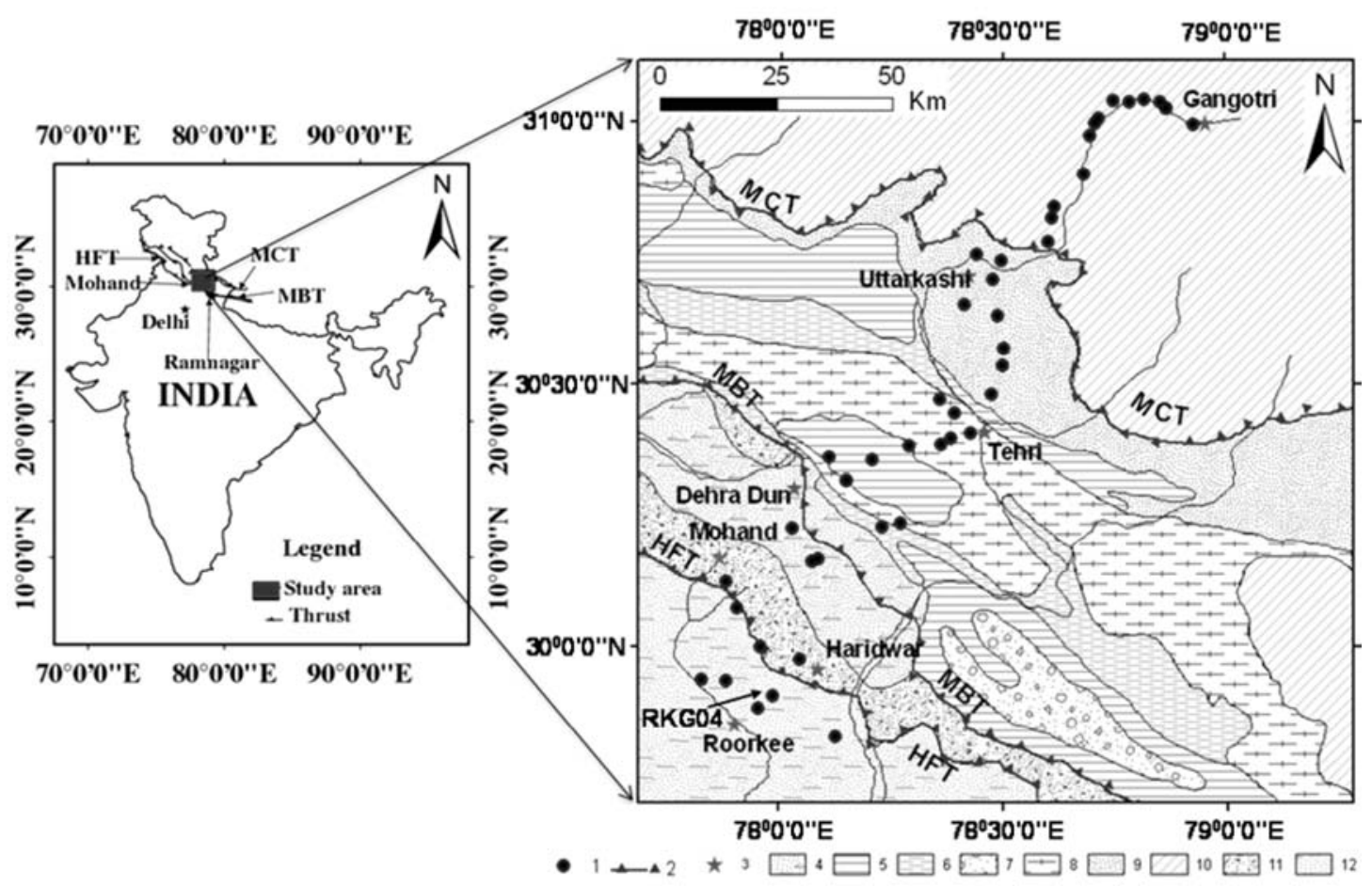

FIGURE 1. Location the study area (geological map compiled from Virdi, 1988, Sorkhabi et al. 1999, Kumar et al. 2002). 1- MT Sites; 2- Thrust; 3- Cities; 4- Dehra Dun Reentrant; 5- Blaini-Infrakrol-Krol; 6- DaMTha; 7- Garwhal Nappe; 8- JaunsarSimla (Undifferentiated); 9- Sunder NagarBerinag Groups; 10- Undifferentiated Metamorphics; 11Undifferentiated Tertiaries; 12- Piedmont zone. MT data collected in the Indo-Gangetic Plains, Siwalik, Lesser and Higher Himalayan region in Garhwal Himalaya. 


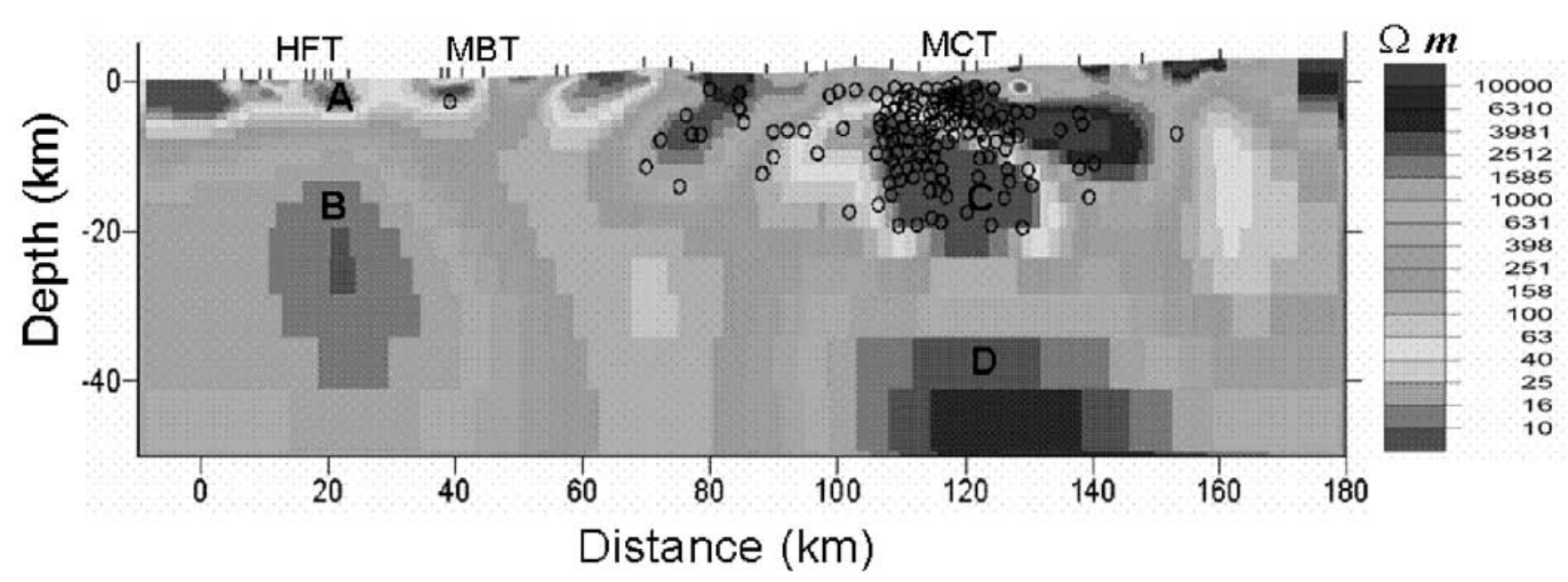

FIGURE 2. 2D resistivity models of Roorkee-Gangotri profile in Garhwal Himalaya corridor with (i) elevation profile on the top, (ii) 2D smooth geoelectric model obtained from the joint inversion of TE, TM responses (iii) the local seismicity (hypocenters) locations plotted as circles in the model, (iv) locations of 27 MT sites indicated by vertical bar, (v) the major Himalayan thrusts (HFT, MBT, MCT).

smooth geoelectric model obtained from the joint inversion of TE and TM responses (ii) the local seismicity (hypocenters) plotted as circle in the electrical model, (iii) elevation profile, (iv) locations of $27 \mathrm{MT}$ sites, used for 2D inversion, indicated by vertical bar, (v) the major Himalayan thrusts.

The electrical model shows a shallow conductive structure $(<50 \Omega m)$ mainly confined in the southern part of the profile located in Indo-Gangetic Plane (IGP) and Lesser Himalayan (LH) region. The conductive structure is extended to a depth of $6 \mathrm{~km}$. Geologically, the zone corresponds to the loose sediments, mollasse of the Miocene and younger age, transported from Higher Himalayan region. Resistive structure $(1000 \Omega m)$ underneath the near surface conductive sediments is interpreted as electrical image of the Indian crust. Low resistivity $(<5 \Omega m)$ zone present below MCT. This zone is a typical example of low resistivity zone in mid crustal region invariably observed in Himalayan region. This zone also appears to coincide with the location of hypocenter of local earthquake. The conducting zone appears to be related with the strain accumulation zone in Himalayan region for future earthquakes. This conductive zone is analogous to the similar conductive zone reported in the central Nepal - Himalaya profile (Lemonnier et al. 1999). The MCT zone falls in high heat flow area, majority of hot spring are concentrated around this zone, might be associated to this low resistivity zone. Resistive feature underlying the low resistivity zone in mid crustal depth is interpreted as the electrical image of north dipping Indian Plate.
References

Arora B R, F E M Lilley, M N Sloane, B P Singh, B J Srivastava and S N. Prasad 1982. Geomagnetic induction and conductive structures in northwest India; Geophysical Journal of Royal Astronomical Society 69: 459-475

Groom RW and RC Bailey. 1989. Decomposition of Magnetotelluric impedance tensors in the presence of local three-dimensional galvanic distortion; Journal of Geophysical Research 94: 1913-1925

Gupta G, SG Gokarn and BP Singh 1994. Thickness of the Siwalik Sediments in the Mohand-Ramnagar region using magnetotelluric studies; Physics of the Earth and Planetary Interiors 83: 217-224

Khattri K N. 1992. Local seismic investigations in the Garhwal-Kumaun Himalaya. Mem. Geol. Soc. India, 23, pp. 45-66

Kumar R, S K Ghosh, S J Sangode and V C Thakur. 2002. Manifestation of Intra - Foreland thrusting in the Neogene Himalaya foreland basin fill; Journal of Geological Society of India 59: 547-560

Lemonnier C, Marquis G, Perrier F, Avouac J P, Chitrakar G, Kafle B, Sapkota S, Gautam U, Tiwari D and Bano M 1999 Electrical structure of the Himalaya of central Nepal: high conductivity around the mid-crustal ramp along the MHT; Geophysical Research Letters 26: 3261-3264

McNeice G W and A G Jones. 2001. Multisite, multifrequency tenser decomposition of magnetotelluric data. Geophysics 66: 158-173

Sorkhabi R B, E Stump, K Foland and A K Jain. 1999. Tectonic and cooling history of the Garhwal Higher Himalaya (Bhagirathi Valley): constraints from thermochronological data; Gondwana Research Group Memoir 6: 217-235

Virdi N S. 1988. Pre - Tertiary geotectonic events in the Himalaya; Z. geol. Wiss, Berlin 16: 571-585 